\title{
Incorporation of Bifidobacterium sp. into powder products through a fluidized bed process for enteric targeted release
}

\author{
Zacnite Sánchez-Portilla, ${ }^{1}$ Luz M. Melgoza-Contreras, ${ }^{2}$ Rosalía Reynoso-Camacho, ${ }^{3}$ Julio I. Pérez-Carreón, ${ }^{4}$ \\ and Angélica Gutiérrez-Nava** \\ ${ }^{1}$ Doctorado en Ciencias Biológicas y de la Salud, Universidad Autónoma Metropolitana, Ciudad de México, CP 14380, México \\ ${ }^{2}$ Departamento de Sistemas Biológicos, División de Ciencias Biológicas y de la Salud, Universidad Autónoma Metropolitana-Xochimilco, \\ Ciudad de México, CP 04960, México \\ ${ }^{3}$ Facultad de Química, Universidad Autónoma de Querétaro, Querétaro, CP 76010, México \\ ${ }^{4}$ Laboratorio de Enfermedades Hepáticas, Instituto Nacional de Medicina Genómica, Ciudad de México, CP 14610, México
}

\begin{abstract}
Considering the increase in evidence regarding the benefits of probiotics on human health, there is interest in developing solid products with proper functional characteristics, such as temperature and $\mathrm{pH}$ stability, that can be added to oral solid dosage forms or to dairy products to release microorganisms directly at their site of action. The aim of this work was to develop a product with an enteric coat containing probiotics that is stable at room temperature and resists low $\mathrm{pH}$ to ensure that the probiotics are passed through the stomach and reach the colon. We obtained 2 enteric-release products based on the incorporation of Bifidobacterium sp. using commercial microcrystalline cellulose (BIP-Av) and prebiotic inulin (BIP-In) as cores. Both products had an initial concentration of approximately $1 \times 10^{8}$ bifidobacteria per gram $(\mathrm{cfu} / \mathrm{g})$ and showed a suitable resistance to acid; complete release from the products at a $\mathrm{pH}$ of 7.5 was observed at $120 \mathrm{~min}$ for BIP-In and 180 min for BIP-Av. The viability of bacteria in both products decreased by approximately 3 orders of magnitude. The death rate constant corresponded to 0.1143 for BIP-Av and 0.1466 for BIP-In, which means that in these storage conditions, the viability decreased slightly. Both products protected bifidobacteria for more than $2 \mathrm{yr}$, delivering a concentration of more than $1 \times 10^{5}$ $\mathrm{cfu} / \mathrm{g}$. Due to these characteristics, the products could be incorporated into solid pharmaceutical forms for oral administration. These products could have significant advantages over existing products on the market and provide protection for bacteria, allowing their passage through the stomach to reach the colon, and the viability of bacteria was maintained after storage at room temperature for more than $1 \mathrm{yr}$.
\end{abstract}

Received March 12, 2020.

Accepted July 29, 2020.

*Corresponding author: agutz@correo.xoc.uam.mx
Key words: microcrystalline cellulose, inulin, probiotic delivery system, fluidized bed drying, probioticcontaining food

\section{INTRODUCTION}

Different microorganisms, including Bifidobacterium and Lactobacillus, have been used in the food industry (Macfarlane et al., 2006; Guarner, 2007; Lee and O'Sullivan, 2010). The beneficial effect of probiotics on animal health depends on the number of viable bacteria in the colon, where bifidobacteria and other anaerobic microorganisms inhabit. The development of probiotic products has become a challenge because the inclusion of probiotics in food exposes microorganisms to stress, such as temperature changes, oxygen, and osmotic shock; in addition, probiotics must survive gastric $\mathrm{pH}$ and bile salts (Dinakar and Mistry, 1994; Stanton et al., 2001; Desmond et al., 2005). The most widely used materials to protect and encapsulate probiotics are biopolymers such as alginate, chitosan, xanthan gum, whey proteins, gelatin, starch, pectin, prebiotic ingredients (e.g., inulin, resistant starch), and carboxymethylcellulose (Sandoval-Castilla et al., 2010; Villa-García et al., 2010; Wani et al., 2016).

Probiotics have been incorporated into pharmaceutical formulations such freeze-dried powders, pellets, tablets, or microcapsules. These products are more stable than products that require refrigeration due to the absence of water. However, their manufacturing continues to be a challenge, especially for anaerobic bacteria such as bifidobacteria, because at different processing stages bacteria face stress conditions such as aeration and temperature changes, resulting in loss of viability (Stummer et al., 2012; Poddar et al., 2014).

Although the microencapsulation technique is frequently used as a bacterial protection method, it does not ensure that probiotics will be released in the intestine because materials generally used for this purpose 
are polymers that form particles with smooth or irregular edges that affect the protection of probiotics. Additionally, they provide little or no resistance to changes in $\mathrm{pH}$, allowing probiotics to be released in the stomach, reducing their viability. An interesting strategy to solve this problem is to coat the particles with enteric polymers to protect them and control their release in the colon (Chen and Chen, 2007; Mortazavian et al., 2007; Solanki et al., 2013).

Enteric coating systems have been designed to protect dosage forms during passage through the stomach and to control the release of active ingredients in the gut, when a drug must be protected from the acidic environment of the stomach until it reaches the intestine for delivering maximum efficacy. Eudragit L and S (Evonik Industries AG, Essen, Germany) are the preferred choice of coating polymers. These materials are anionic copolymers of methacrylic acid and methyl methacrylate. They are insoluble at low $\mathrm{pH}$ but form salts and dissolve above $\mathrm{pH} 6$ and 7, respectively (Ali and Rahman, 2008; Sareen et al., 2014; Evonik Industries, 2015; Li et al., 2015; Patra et al., 2017). This is especially helpful for therapies that rely on targeted drug release in the high-pH colon area-for example, the local treatment of intestinal disorders such as Crohn's disease, ulcerative colitis, or intestinal cancer, for which probiotic-based treatments have also been designed. Different authors have reported the use of products based on Eudragit S100 to protect tablets and pellets containing different strains of Lactobacillus, finding that the coating improves the viability and resistance of microorganisms under acidic conditions (Villena et al., 2015; Dodoo et al., 2017; Mohanta et al., 2019; Pourjafar et al., 2020).

The objective of this study was to develop a targetedrelease powder product using the advantages of a fluidized bed process with a suitable particle size that can be incorporated in pharmaceutical or food formulations, which contain the probiotic Bifidobacterium sp. as an active ingredient and microcrystalline cellulose and inulin as cores, with the protection of an enteric polymer, thus improving the viability of bacteria and their release in the intestine as well as the stability of the stored product.

\section{MATERIALS AND METHODS}

\section{Bacterial Growth and Bacterial Cell Suspension}

A Bifidobacterium sp. strain was used to inoculate TPY-I broth (Difco, Franklin Lakes, NJ) enriched with $1 \%$ inulin (Sigma-Aldrich, St. Louis, MO) under anaerobic conditions with an initial optical density at a wavelength of $660 \mathrm{~nm}\left(\mathrm{OD}_{660}\right)$ of 0.1 . Incubation was carried out at $37^{\circ} \mathrm{C}$ with agitation at $120 \mathrm{rpm}$ for $48 \mathrm{~h}$. The culture was centrifuged for $10 \mathrm{~min}$ at $1,500 \times g$ and $27^{\circ} \mathrm{C}$; the supernatant was removed, and the cells were rinsed with physiological saline solution. To carry out the process of incorporating bifidobacteria on an inert core as microcrystalline cellulose or inulin in the fluidized bed, an agglutination suspension was needed in which the bacteria were kept to be able to include them in the process. The choice of suitable materials for the incorporation depends on the properties of the active agent (Vasisht, 2014). The cell pellet was resuspended in a mixture containing skim milk to give microorganisms physical protection, hydroxypropyl methylcellulose as binder, and physiological saline solution as dispersion medium. A sample was taken to determine viability.

\section{Incorporation and Protection of Bifidobacteria with an Enteric Polymer}

Two cores were selected for the incorporation of bifidobacteria, microcrystalline cellulose due to its technological characteristics and inulin for its prebiotic properties. Two fluidized bed processes were carried out. First, the bacteria were incorporated into microcrystalline cellulose: Avicel (BIP-Av; FMC BioPolymer, Philadelphia, PA) or inulin (BIP-In; OraftiBeneo, Mannheim, Germany). One hundred grams of each sample was placed in the fluid bed chamber (Aeromatic Fielder AG, Bubendorf, Switzerland), and the bacterial cell suspension was transferred into the fluid bed chamber using a peristaltic pump. In the fluid bed process, the granules of each core were coated with the bacterial suspension until dry granules with bifidobacteria were obtained. For the second process, each product was coated with an enteric polymer (Eudragit S12.5); the polymer was dispersed in an organic solution with $8 \%$ total solids, as indicated in the technical data sheet (Evonik Industries, 2015), and the final suspension was transferred into the fluid bed chamber using a peristaltic pump. For both cases, the conditions of the fluid bed process to obtain spherical granules of homogeneous size and sphericity were optimized at a chamber pressure of 3 bar, an average atomization rate of $5.8 \mathrm{~g} / \mathrm{min}$, and a temperature of approximately $35 \pm$ $2^{\circ} \mathrm{C}$. The products obtained were stored at room temperature in polypropylene bags until further analysis.

\section{Physical Characterization of Products}

Particle Size and Moisture Content. The particle size of the cores and their respective obtained products was analyzed with a laser diffraction system (Partica, LA950, Horiba Scientific, Piscataway, NJ), and the data presented are the average of the mean 
particle size distribution from 3 different experiments. The moisture content was determined using a thermobalance (OHAUS, MB45) at $100^{\circ} \mathrm{C}$ for $10 \mathrm{~min}$.

Morphology and Surface Analysis. The morphology and particle surface of the products were analyzed using a digital microscope (DinoLite, Hsinchu City, Taiwan) at $50 \times$ magnification and on a scanning electron microscope (JSM-59000 LV, Jeol USA, Peabody, MA). For control purposes, the core with incorporated bacteria and without enteric coating was also analyzed. To observe the morphology of bifidobacteria on a scanning electron microscope, a sample of Bifidobacterium sp. was centrifuged and rinsed to remove the medium. Subsequently, to fix and dehydrate cells, the methodology described by Tang et al. (2017) was used. To determine the circularity of the cores and products, images were processed with the particle analysis tool from ImageJ (https://imagej.net).

\section{Total Viable Count}

The amount of Bifidobacterium sp. in the bacterial suspension and in the obtained products was determined by viable count. Decimal serial dilutions were placed on plates in triplicate with de Man, Rogosa and Sharpe (MRS)-C agar (Difco) enriched with L-HCl-Cysteine (J. T. Baker, Sigma-Aldrich) for each dilution. Afterward, they were incubated under anaerobiosis at $37^{\circ} \mathrm{C}$ for $72 \mathrm{~h}$. Colonies were counted, and the number of living bacteria per milliliter of suspension was calculated.

\section{Product Resistance in Acetate Buffer and Phosphate Buffer}

Fifty milligrams of each product was placed in acetate buffer ( $\mathrm{pH}$ 3) with constant agitation for $1 \mathrm{~h}$. Aliquots were taken at 0 and $60 \mathrm{~min}$; afterward, the medium was centrifuged, and the bacteria were transferred to phosphate buffer ( $\mathrm{pH}$ 7.5) and kept at constant agitation for $4 \mathrm{~h}$. Aliquots were taken at different time points (0, 60, 120, 180, and $240 \mathrm{~min})$. Decimal serial dilutions of bacterial aliquots were inoculated in triplicate on petri dishes with MRS-C medium and incubated under anaerobiosis at $37^{\circ} \mathrm{C}$ for $72 \mathrm{~h}$. The colonies were counted, and the number of living bacteria per milliliter of suspension was calculated. Free Bifidobacterium sp. at a concentration equivalent to $50 \mathrm{mg}$ of each entericrelease product was also assayed as a control.

\section{Viability of the Products over Time}

Powder products were stored at room temperature $\left(25^{\circ} \mathrm{C}\right.$ and $33 \%$ relative humidity) in closed polypropylene bags. Both moisture content and Bifidobacterium sp. viability in the products were evaluated $0,1,2,3$, and 24 mo after production.

\section{Statistical Analysis}

Data analysis was carried out using Prism 8 (GraphPad Software Inc., La Jolla, CA) with an ANOVA, followed by a Tukey test to determine significant differences between the obtained products. A difference with $P<0.05$ was considered statistically significant.

\section{RESULTS AND DISCUSSION}

\section{Total Viable Count}

In the present work, we obtained 2 enteric powder products containing Bifidobacterium sp.: BIP-Av and BIP-In. During the manufacture of products, bacterial viability was monitored. The initial concentration of Bifidobacterium $\mathrm{sp}$. was approximately $1 \times 10^{9} \mathrm{cfu} / \mathrm{mL}$. Although the viability was reduced by $0.99 \log _{10} \mathrm{cfu} / \mathrm{g}$ with the BIP-Av product and $1.33 \log _{10} \mathrm{cfu} / \mathrm{g}$ with the BIP-In product, the remaining viability exceeded $1 \times 10^{8} \mathrm{cfu} / \mathrm{mL}$ (Figure 1 ). The loss of viability can be attributed to the aeration conditions of the process because Bifidobacterium sp. is an anaerobic microorganism. However, the number of live bacteria within the products remained high with respect to the initial concentration.

\section{Characterization of Enteric-Release Products}

Particle Form, Appearance, and Circularity. The products had the appearance of a white powder, which appeared as homogeneous granules with irregular edges under the microscope (Figure 2, panels A3 and B3). To determine the circularity of the particles, the images were analyzed with a value of 1 used for a perfect circle. This analysis showed that the circularity of the microcrystalline cellulose used as core and its respective product (BIP-Av) had a mean value of 0.92 (Figure 2, panels A1 and A2). On the other hand, the inulin used as core had a circularity of 0.87 , and its respective product (BIP-In) had a circularity of 0.92 (Figure 2, panels B1 and B2). The granules of inulin were distinguished as irregular aggregates of smaller spherical particles, and the appearance of these granules was modified when subjected to the fluidized bed process.

Fluidized bed processes improve the physical characteristics of some materials, including the sphericity, circularity, and rheology, especially for materials that do not have good flow properties due to their nature or particle size, as is the case with inulin. However, mate- 


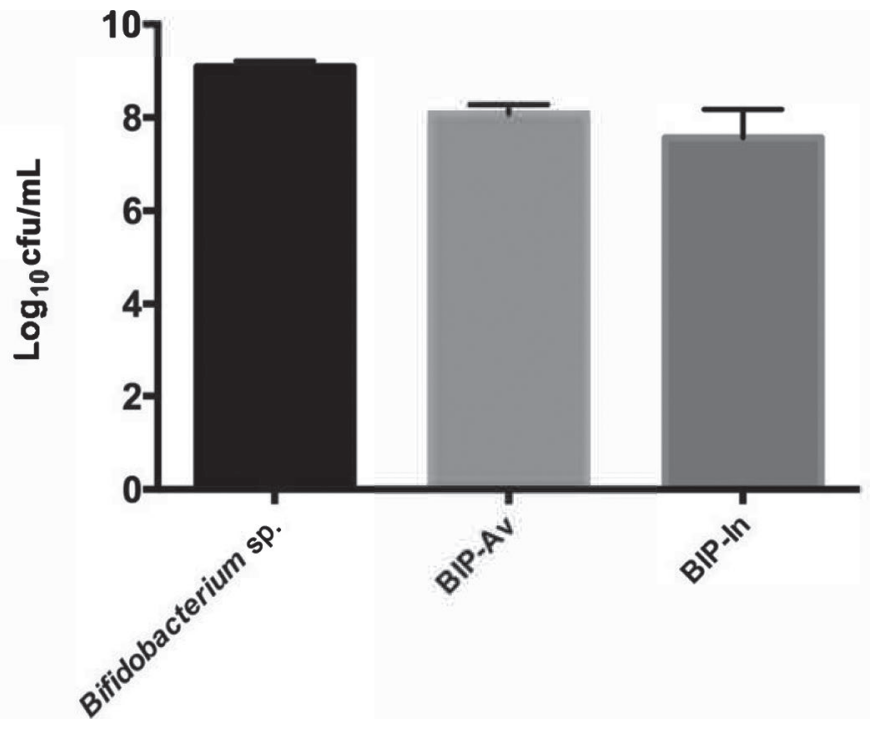

Figure 1. The viability of Bifidobacterium sp. initially and in 2 enteric-release products based on the incorporation of Bifidobacterium sp. using commercial microcrystalline cellulose (BIP-Av) and prebiotic inulin (BIP-In) as cores. The statistical analysis showed that there was no significant difference between the bifidobacteria concentration before and after obtaining the product on the fluidized bed. The experiment was determined at $\mathrm{pH} 7.5$ after 120 min under agitation and carried out in triplicate. Bars show SD.

rials with good flow properties, such as microcrystalline cellulose, are not modified by the fluidized bed process (Fukumori and Ichikawa, 2003; de Barros et al., 2015). The physical and chemical properties of the cores play an important role in the incorporation of bifidobacteria and the maintenance of their viability. For BIP-Av, bifidobacteria were quantified as $2.20 \times 10^{8} \mathrm{cfu}$, and for BIP-In, bifidobacteria were quantified as $1.0 \times 10^{8} \mathrm{cfu}$.

Particle Size. The initial particle size of each of the cores used in the process was $183.44 \mu \mathrm{m}$ for microcrystalline cellulose and $136.74 \mu \mathrm{m}$ for inulin. After the process, the particle size of the BIP-Av product increased by $85.8 \mu \mathrm{m}$ and that of BIP-In increased by $122.3 \mu \mathrm{m}$. These differences can be explained by the fact that microcrystalline cellulose is a free-flowing material that does not form particle agglomerates during fluidized bed granulation processes and increases in size only when solids are added to its surface. In contrast, inulin is classified as an adhesive material whose particles adhere to each other during fluidized bed granulation processes to form larger granules in addition to the solids added to the surface (Figure 2B; Brittain, 2001). The final average diameter of the products was $269.24 \mu \mathrm{m}$ for BIP-Av and $260.04 \mu \mathrm{m}$ for BIP-In.

Particle size is important. Attempts have been made to coat granules and spheres of different Lactobacillus species obtained mainly by extrusion and granulation with enteric polymers, and tests have verified that un- der simulated gastric conditions, these coatings provide high levels of protection to cells (Pyar and Peh, 2014; De Barros et al., 2015). However, although they can carry a good probiotic load, the products obtained have an average particle size of $1 \mathrm{~mm}$, limiting their use for incorporation in fermented foods such as yogurts, because the texture of the particles results in an unpleasant sensation in the mouth.

Particle Size Distribution. Samples of the different products were analyzed to determine the homogeneity of the distribution of their particles. The obtained results showed a single population in both products, and the coefficients for BIP-Av (2.5) and BIP-In (3.1) were consistent, showing that the products were uniform because the dispersion between the particle sizes was narrow. As this value increased, batch homogeneity was lost.

Scanning Electron Microscopy. The micrographs obtained by scanning electron microscopy allowed us to observe the characteristics of the surfaces of each core (microcrystalline cellulose and inulin) as well as their products. Microcrystalline cellulose was observed as granules with a rough surface of homogeneous size and shape. After the fluidized bed processes, aggregates of inulin formed spherical particles of different sizes with smooth surfaces and irregular granules with rough surfaces (Figure 3). The use of inulin as a core for the incorporation of probiotics provided an advantage over the use of microcrystalline cellulose because it is a prebiotic for the optimal development of bifidobacteria in the colon.

Moisture Content. The viability of bacteria during storage depends on moisture content, which in turn is influenced by the relative humidity during storage (Gunning et al., 1995; Champagne et al., 1996; Hsiao et al., 2004; Miao et al., 2008; Poddar et al., 2014). The moisture content in BIP-Av and BIP-In was determined during mo 1, 2, and 3 and after 24 mo of storage. For BIP-Av, the moisture content remained unchanged at $24 \mathrm{mo}$, with a value of $4.5 \%$, whereas the moisture content of the BIP-In product increased from 3.73 to $4.77 \%$. Both products were stored under the same conditions; therefore, this result can be attributed to the chemical nature of inulin because it is more hygroscopic than microcrystalline cellulose. In addition, to prevent loss of viability, solid products with low water contents can have enhanced physical characteristics and fluidity, which are important for the production of solid dosage forms (Onwulata et al., 1995).

Bifidobacterium sp. Viability During a Storage Period. The viability of the bacteria during the storage period was determined by measuring the survival of Bifidobacterium sp. in BIP-Av and BIP-In products. Figure 4 shows the survival of bacteria in each prod- 

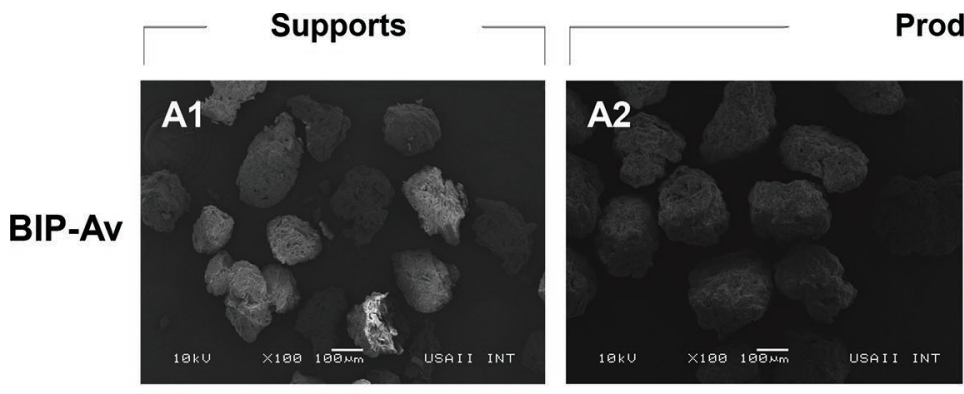

Products
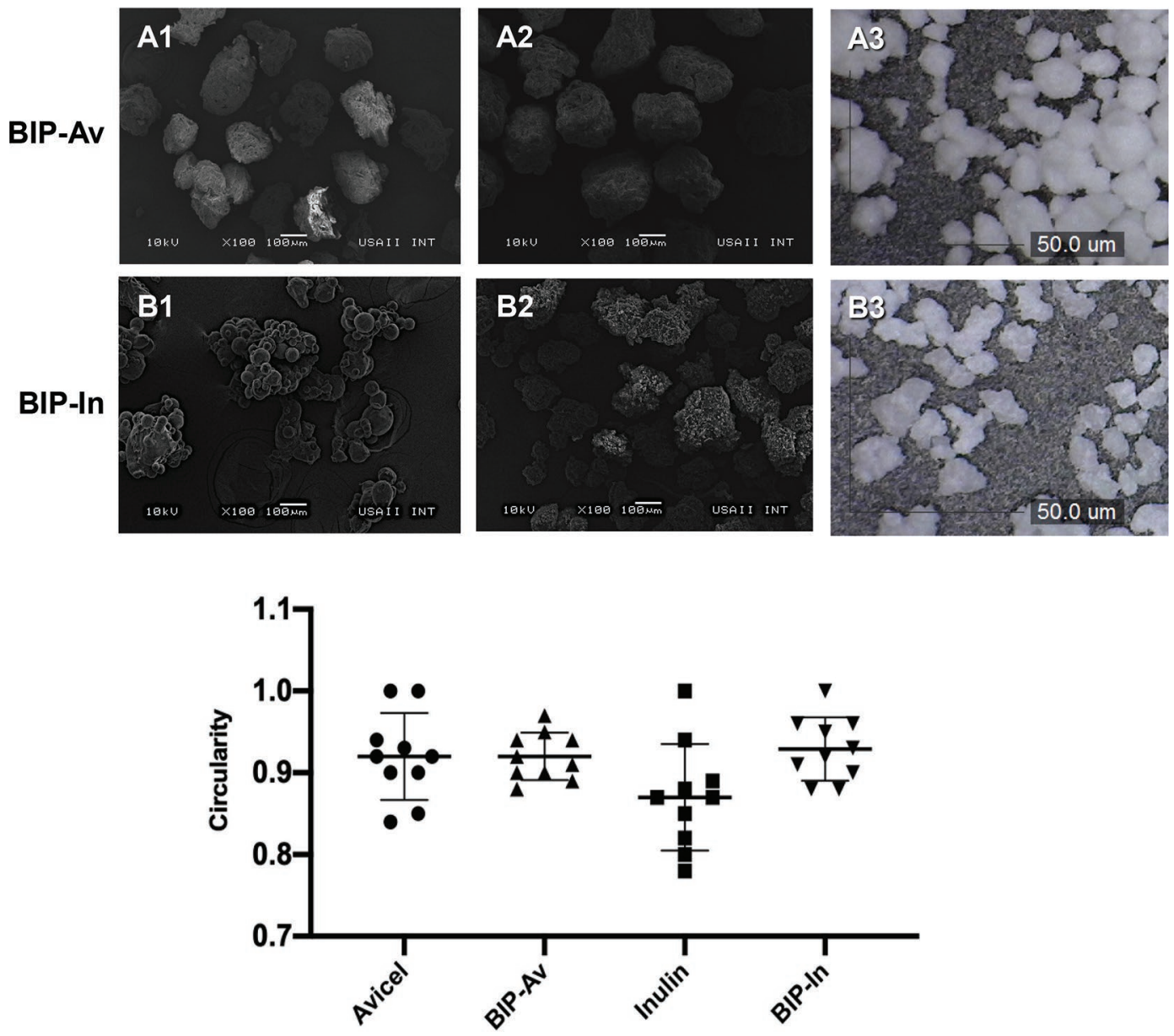

Figure 2. Top: microscopic appearance and circularity of 2 enteric-release products based on the incorporation of Bifidobacterium sp. using commercial microcrystalline cellulose (Avicel; BIP-Av; FMC BioPolymer, Philadelphia, PA) and prebiotic inulin (BIP-In) as cores. Micrographs were obtained using scanning electron microscopy. Panel A1: microcrystalline cellulose. Panel A2: enteric-release product with microcrystalline cellulose as the core (BIP-Av). Panel B1: inulin. Panel B2: enteric-release product with inulin as the core (BIP-In). Panels A3 and B3: BIP-Av and BIP-In, respectively, observed on a digital microscope $(50 \times$ magnification, Dino-Lite, Hsinchu City, Taiwan). Bottom: analysis of the circularity of microcrystalline cellulose, inulin, and their corresponding products (BIP-Av and BIP-In). The analysis does not show a statistically significant difference. The results represent an average of 10 measurements \pm SD.

uct. During the first 3 mo of analysis, the viability was maintained at $6.6 \log _{10} \mathrm{cfu} / \mathrm{g}$ for both products, and after $2 \mathrm{yr}$, the viability of the obtained products remained at $4.99 \log _{10} \mathrm{cfu} / \mathrm{g}$ for BIP-Av and $4.61 \log _{10}$ $\mathrm{cfu} / \mathrm{g}$ for BIP-In, with no statistically significant difference in the loss of viability of both products during the storage period.

The use of excipients such microcrystalline cellulose and inulin as well as the fluidization process allowed us to obtain products that maintained the viability of $B i$ fidobacterium sp. during incorporation and protection processes and ensured its resistance to acidic conditions. These products are optimal for the formulation of dosage forms that enable bifidobacteria to be localized to a specific action site (Kim et al., 2016) and maintain the viability of Bifidobacterium for long storage periods. Nag and Das (2013) reportedly obtained a product from a mixture of Lactobacillus and Bifidobacterium on a suspension with powdered milk by means of a fluidized bed drying process. The initial viability was 9.5 $\log _{10} \mathrm{cfu} / \mathrm{g}$, which decreased to $7.7 \log _{10} \mathrm{cfu} / \mathrm{g}$ during the first 12 wk, and by the end of 52 wk of storage at $25^{\circ} \mathrm{C}$, the viability was $2.7 \log _{10} \mathrm{cfu} / \mathrm{g}$.

\section{Resistance Tests at pH 3.0 and Release at pH 7.5}

Bifidobacterium sp. Culture. Bifidobacterium sp. was subjected to different $\mathrm{pH}$ conditions. Figure 5 shows that the viability of Bifidobacterium sp. decreased by $1.35 \log _{10} \mathrm{cfu} / \mathrm{g}$ during the first hour at $\mathrm{pH}$ 
3. At $\mathrm{pH} 7.5$, the viability was reduced to $4 \log _{10} \mathrm{cfu} / \mathrm{g}$ $3 \mathrm{~h}$ after starting the experiment. This shows that the culture without any protection had low resistance to these conditions.

Probiotic Products. Resistance was determined considering the amount of released bacteria during the experiment. In the first hour under acidic $\mathrm{pH}$ conditions, no bifidobacteria were released from the products. The initial concentration at time 0 was due to bacteria that adhered to the surface of granules, which were not coated. At pH 7.5 (Eudragit S12.5 solubility $\mathrm{pH}$ ), the complete release of bifidobacteria was observed at $180 \mathrm{~min}$ for BIP-In and at $240 \mathrm{~min}$ for BIP-Av (Figure $5)$. Because inulin is highly water soluble, the product can be hydrated more easily and therefore bacteria can be released from the core. In contrast, microcrystalline cellulose retains bifidobacteria because it has high porosity and low solubility in water (Rowe et al., 2009), resulting in a better resistance under the analysis condition. Therefore, the use of inulin as core to obtain a targeted-release product is limited because bifidobacteria are retained in the granules for a shorter time under alkaline $\mathrm{pH}$ conditions compared with microcrystalline cellulose.

Considering that no bifidobacteria were released under acidic $\mathrm{pH}$ conditions, Figure 6 presents the release analysis of bifidobacteria from BIP-Av and BIP-In products at $\mathrm{pH}$ 7.5. We observed that for the first hour
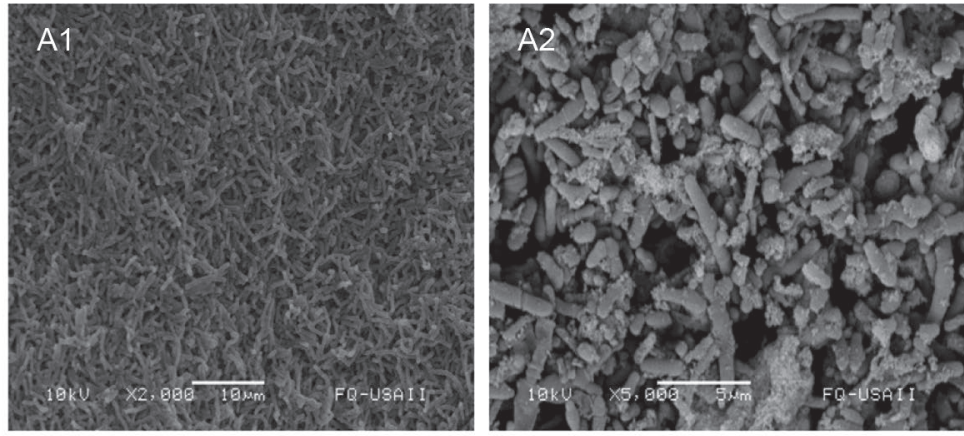

\section{Support}
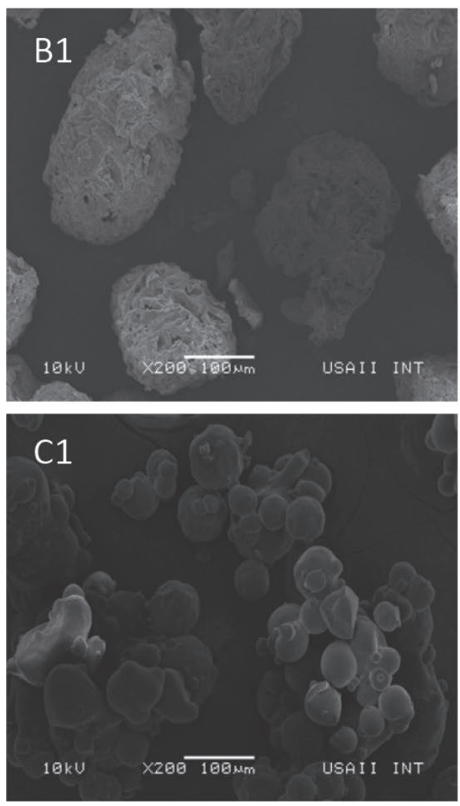

Incorporated Bifidobacterium
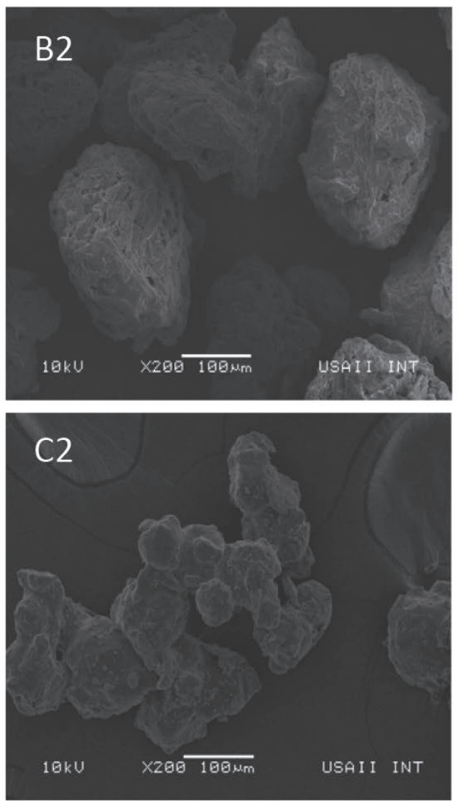

Enteric product
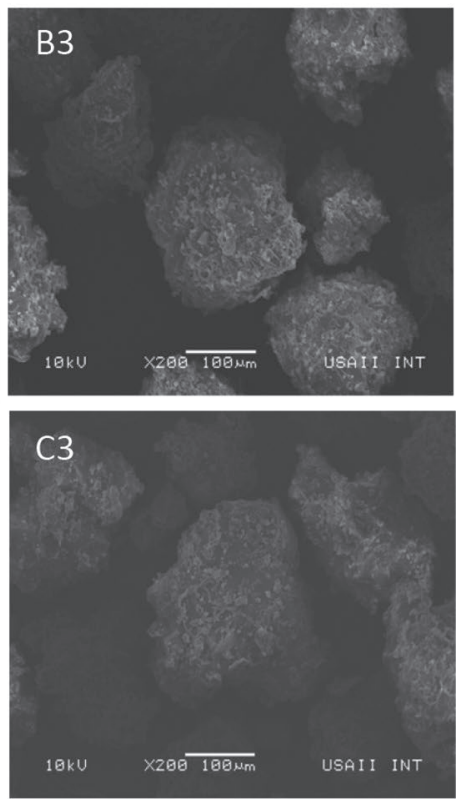

Figure 3. Surface characteristics of substrates and products using scanning electron microscopy. Panel A1: morphology of Bifidobacterium sp. in the culture medium. Panel A2: Bifidobacterium sp. incorporated in a suspension containing skim milk and hydroxypropyl methylcellulose. Panel B1: microcrystalline cellulose granules. Panel B2: microcrystalline cellulose with the bacteria incorporated before being coated. Panel B3: enteric-release product based on the incorporation of Bifidobacterium sp. using commercial microcrystalline cellulose (BIP-Av) as core. Panel C1: inulin granules. Panel C2: inulin with the bacteria incorporated before being coated. Panel C3: enteric-release product based on the incorporation of Bifidobacterium sp. using prebiotic inulin (BIP-In) as core. 


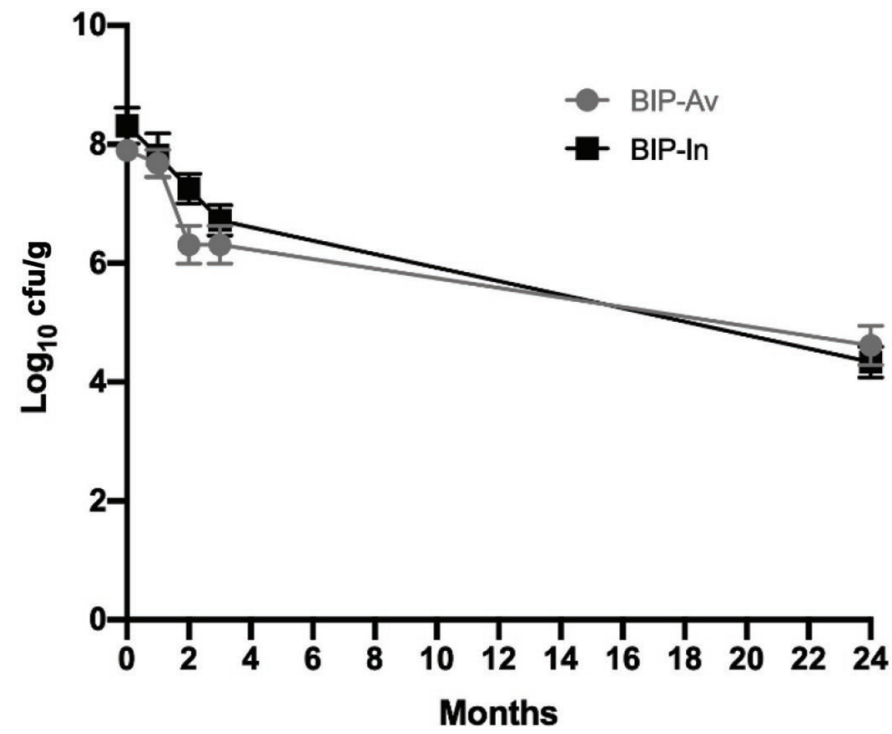

Figure 4. Survival of Bifidobacterium sp. on 2 enteric-release products based on the incorporation of Bifidobacterium sp. using commercial microcrystalline cellulose (BIP-Av) and prebiotic inulin (BIP-In) as cores after 1,2,3, and 24 mo of analysis. After $24 \mathrm{mo}$, the difference in the loss of viability between products was significant $(P<0.01)$. The graph shows the average of 3 repetitions \pm SD.

of analysis, there was a statistically significant difference $(P<0.001)$ between the release of bifidobacteria. However, the release throughout the experiment (240 min) was compared, and a significant difference between BIP-Av and BIP-In was not observed.

In recent years, attempts have been made to develop methods for obtaining solid probiotic-based products used as functional supplements in easily administered and stored forms that do not require refrigeration and protect microorganisms from the adverse conditions of the gastrointestinal tract (Lian et al., 2002; MattilaSandholm et al., 2002; Khani et al., 2012). The use of other methacrylate-based polymers has been reported; De Barros et al. (2014) designed a laminated polymer film formulation for enteric delivery of live vaccine and probiotic bacteria. A Eudragit L 100-55-based polymeric laminate successfully protected dried probiotic or vaccine live bacterial cells from simulated gastric fluid for $2 \mathrm{~h}$ and subsequently released all viable cells within $60 \mathrm{~min}$ of transfer into simulated intestinal fluid. Lactobacillus acidophilus and Escherichia coli were encapsulated with Eudragit RS100 and Eudraguard, and the microparticles showed good resistance to simulated intestinal fluid and a microorganism load of 90.2 and $57.3 \%$, respectively (Yus et al., 2019). In 2015 , the development of a formulation of pellets based on Lactobacillus casei coated with Acryl-Eze (Eudragit L100-55) was reported; uncoated spheres gave partial acid protection, but enteric coated spheres effectively

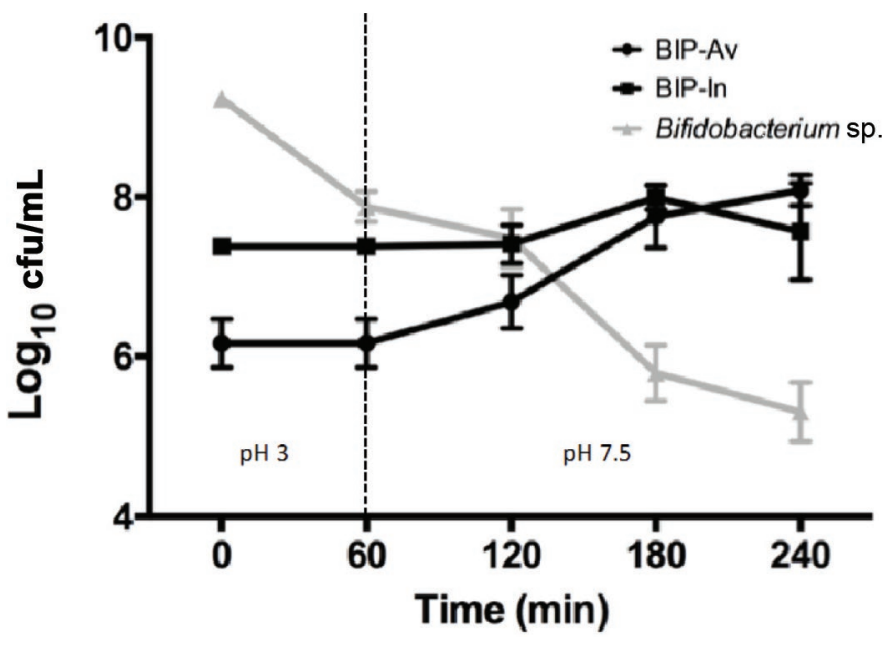

Figure 5. The resistance of Bifidobacterium sp. from culture and from 2 enteric-release products based on the incorporation of Bifidobacterium sp. using commercial microcrystalline cellulose (BIP$\mathrm{Av})$ and prebiotic inulin (BIP-In) as cores in acetate buffer, $\mathrm{pH} 3(0$ and $60 \mathrm{~min}$ ), and in phosphate buffer, $\mathrm{pH} 7.5$ (120, 180, and $240 \mathrm{~min})$. The average of 3 repetitions $\pm \mathrm{SD}$ is shown.

protected dried probiotic live bacterial cells from acid for $2 \mathrm{~h}$ and subsequently released all viable cells within $1 \mathrm{~h}$ of transfer into simulated intestinal fluid (De Barros et al., 2014, 2015; Yus et al., 2019).

The design of probiotic-based modified-release products is a promising alternative to solve the main stability problems that occur during production and storage and to ensure that the probiotics are resistant to the

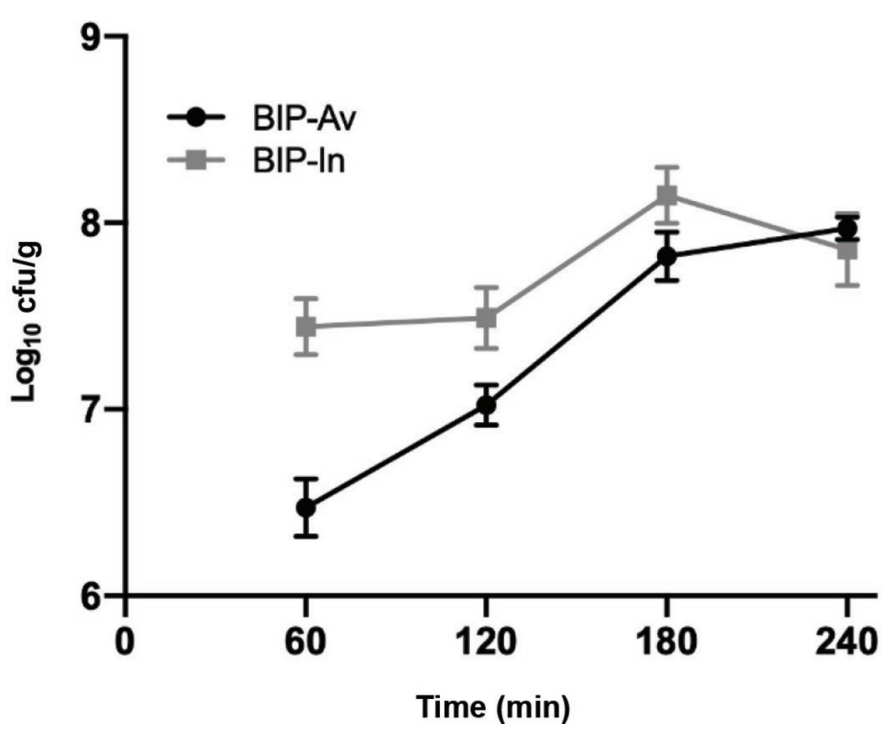

Figure 6. Release of Bifidobacterium sp. from 2 enteric-release products based on the incorporation of Bifidobacterium sp. using commercial microcrystalline cellulose (BIP-Av) and prebiotic inulin (BIPIn) as cores at $\mathrm{pH}$ 7.5. The first hour of analysis showed a significant difference $(P<0.001)$. The average of 3 repetitions \pm SD is shown. 
adverse conditions of the gastrointestinal tract, as they require passage through the stomach and small intestine to reach the colon and exert their beneficial effects (de Vos et al., 2010; Barbosa et al., 2017).

\section{CONCLUSIONS}

Due to the increase in reports regarding the benefits of probiotic consumption on human and animal health, new products need to be developed to maintain the cell viability of probiotic microorganisms until they are consumed and ensure product stability under storage conditions. We obtained 2 enteric-release products based on bifidobacteria that possess good physical and technological characteristics and a high microorganism concentration $\left(10^{8} \mathrm{cfu} / \mathrm{g}\right.$ of product). Both products resisted stomach acidic conditions of $\mathrm{pH} 3$. The difference between the 2 products lies in the mechanism of release of bifidobacteria from the granules. Due to the water solubility of inulin in the BIP-In product, the release of bifidobacteria is dependent only on the protection polymer, whereas for BIP-Av, in addition to the protection polymer, the microcrystalline cellulose particles keep bacteria retained by providing a greater resistance even under alkaline conditions. These characteristics allow the bacteria to adapt to the needs of the products in which they will be incorporated (e.g., products for human consumption such as food supplements contained in capsules or tablets, or in dairy products such as powdered milk, milkshakes, yogurts, or ice creams) with the aims of conferring added value to products for daily consumption and maintaining the viability of the bacteria for long storage periods. This can ensure a fast and affordable process, which is good for the manufacture of products that optimize the amount of administered probiotic and maximize the effects on those who consume them. Most orally administered dosage forms are solid and are manufactured by means of powder formulation and processing. The study of the physical properties of particles with an important role in the manufacturing of these products is important because it makes it possible to predict and avoid any issues during manufacture and improves quality characteristics.

\section{ACKNOWLEDGMENTS}

We are grateful to CONACyT for the support (Consejo Nacional de Ciencia y Tecnología, Ciudad de México, México; grant number 457644). We thank Eng. Iván Puente Lee (USAII/UNAM, Unidad de Servicios de Apoyo a la Investigación y a la Industria, Universidad Nacional Autónoma de México, Ciudad de México) for the scanning electron microscopy experiments and MegaFarma for the kind donation of inulin-
GR (granulated; Orafti-Beneo, Mannheim, Germany). The authors have not stated any conflicts of interest.

\section{REFERENCES}

Ali, J., and M. A. Rahman. 2008. Development and in vitro evaluation of enteric coated multiparticulate system for resistant tuberculosis. Indian J. Pharm. Sci. 70:477. https://doi.org/10.4103/0250-474X .44597.

Barbosa, J. A., B. C. Conway, and H. A. Merchant. 2017. Going natural: Using polymers from nature for gastroresistant applications. Br. J. Pharmacol. 2:1-17. https://doi.org/10.5920/bjpharm.2017 .01 .

Brittain, H. G. 2001. Solid-state analysis. Pages 57-73 in Handbook of Modern Pharmaceutical Analysis. S. Ahuja and S. Scypinski, ed. Academic Press, San Diego, CA.

Champagne, C. P., F. Mondou, Y. Raymond, and D. Roy. 1996. Effect of polymers and storage temperature on the stability of freezedried lactic acid bacteria. Food Res. Int. 29:555-562. https://doi .org/10.1016/0963-9969(95)00050-X.

Chen, M.-J., and K.-N. Chen. 2007. Applications of probiotic encapsulation in dairy products. Pages 83-112 in Encapsulation and Controlled Release: Technologies in Food Systems. J. M. Lakkis, ed. Wiley-Blackwell, Hoboken, NJ.

de Barros, J., T. Lechner, D. Charalampopoulos, V. V. Khutoryanskiy, and A. D. Edwards. 2015. Enteric coated spheres produced by extrusion/spheronization provide effective gastric protection and efficient release of live therapeutic bacteria. Int. J. Pharm. 493:483-494. https://doi.org/10.1016/j.ijpharm.2015.06.051.

De Barros, J. M., T. Scherer, D. Charalampopoulos, V. V. Khutoryanskiy, and A. D. Edwards. 2014. A laminated polymer film formulation for enteric delivery of live vaccine and probiotic bacteria. J. Pharm. Sci. 103:2022-2032. https://doi.org/10.1002/jps.23997.

de Vos, P., M. M. Faas, M. Spasojevic, and J. Sikkema. 2010. Encapsulation for preservation of functionality and targeted delivery of bioactive food components. Int. Dairy J. 20:292-302. https://doi .org/10.1016/j.idairyj.2009.11.008.

Desmond, C. B., M. Corcoran, M. Coakley, G. F. Fitzgerald, R. P. Ross, and C. Stanton. 2005. Development of dairy-based functional foods containing probiotics, and prebiotics. Aust. J. Dairy Technol. 60:121-126.

Dinakar, P., and V. V. Mistry. 1994. Growth and viability of Bifidobacterium bifidum in cheddar cheese. J. Dairy Sci. 77:2854-2864. https://doi.org/10.3168/jds.S0022-0302(94)77225-8.

Dodoo, C. C., J. Wang, A. W. Basit, P. Stapleton, and S. Gaisford. 2017. Targeted delivery of probiotics to enhance gastrointestinal stability and intestinal colonization. Int. J. Pharm. 530:224-229. https://doi.org/10.1016/j.ijpharm.2017.07.068.

Evonik Industries. 2015. Technical information. Eudragit L 12.5 and Eudragit S 12.5. Accessed Feb. 2019. https://healthcare .evonik.com/product/health-care/en/pharmaceuticals/oral-drug -delivery/oral-excipients/eudragit-portfolio/delayed-release/.

Fukumori, Y., and H. Ichikawa. 2003. Fluid bed processes for forming functional particles. Pages 1-7 in Encyclopedia of Pharmaceutical Technology. J. Swarbrick and J. C. Boylan, ed. Marcel Dekker Inc., New York, NY. https://doi.org/10.1081/E-EPT 120018218.

Guarner, F. 2007. Studies with inulin-type fructans on intestinal infections, permeability, and inflammation. J. Nutr. 137:2568S-2571S. https://doi.org/10.1093/jn/137.11.2568S.

Gunning, A. P., A. R. Kirby, V. J. Morris, B. Wells, and B. E. Brooker. 1995. Imaging bacterial polysaccharides by AFM. Polym. Bull. 34:615-619. https://doi.org/10.1007/BF00423359.

Hsiao, H. C., W. C. Lian, and C. C. Chou. 2004. Effect of packaging conditions and temperature on viability of microencapsulated bifidobacteria during storage. J. Sci. Food Agric. 84:134-139. https:/ /doi.org/10.1002/jsfa.1616.

Khani, S., H. M. Hosseini, M. Taheri, M. R. Nourani, and A. A. ImaniFooladi. 2012. Probiotics as an alternative strategy for prevention and treatment of human diseases: A review. Inflamm. Allergy Drug Targets 11:79-89. https://doi.org/10.2174/187152812800392832. 
Kim, J., N. Muhammad, B. H. Jhun, and J.-W. Yoo. 2016. Probiotic delivery systems: A brief overview. J. Pharm. Investig. 46:377-386. https://doi.org/10.1007/s40005-016-0259-7.

Lee, J. H., and D. J. O'Sullivan. 2010. Genomic insights into bifidobacteria. Microbiol. Mol. Biol. Rev. 74:378-416. https://doi.org/ 10.1128/MMBR.00004-10.

Li, P., Z. Yang, Y. Wang, Z. Peng, S. Li, L. Kong, and Q. Wang. 2015. Microencapsulation of coupled folate and chitosan nanoparticles for targeted delivery of combination drugs to colon. J. Microencapsul. 32:40-45. https://doi.org/10.3109/02652048.2014.944947.

Lian, W.-C., H.-C. Hsiao, and C.-C. Chou. 2002. Survival of bifidobacteria after spray-drying. Int. J. Food Microbiol. 74:79-86. https:// doi.org/10.1016/S0168-1605(01)00733-4.

Macfarlane, S., G. T. Macfarlane, and J. H. Cummings. 2006. Review article: Prebiotics in the gastrointestinal tract. Aliment. Pharmacol. Ther. 24:701-714. https://doi.org/10.1111/j.1365-2036.2006 .03042.x.

Mattila-Sandholm, T., P. Myllärinen, R. Crittenden, G. Mogensen, R. Fondén, and M. Saarela. 2002. Technological challenges for future probiotic foods. Int. Dairy J. 12:173-182.

Miao, S., S. Mills, C. Stanton, G. F. Fitzgerald, Y. Roos, and R. P. Ross. 2008. Effect of disaccharides on survival during storage of freeze-dried probiotics. Dairy Sci. Technol. 88:19-30. https://doi .org/10.1051/dst:2007003.

Mohanta, S., S. K. Singh, B. Kumar, M. Gulati, R. Kumar, A. K. Yadav, S. Wadhwa, J. Jyoti, S. Som, K. Dua, and N. K. Pandey. 2019. Efficacy of co-administration of modified apple polysaccharide and probiotics in guar gum-Eudragit S100 based mesalamine mini tablets: A novel approach in treating ulcerative colitis. Int. J. Biol. Macromol. 126:427-435. https://doi.org/10.1016/j.ijbiomac .2018.12.154.

Mortazavian, A., S. H. Razavi, M. E. Ehsani, and S. Sohrabvandi. 2007. Principles and methods of microencapsulation of probiotic microorganisms. Iranian J. Biotechnol. 5:1-18.

Nag, A., and S. Das. 2013. Improving ambient temperature stability of probiotics with stress adaptation and fluidized bed dry. J. Funct. Foods 5:170-177. https://doi.org/10.1016/j.jff.2012.10.001.

Onwulata, C., P. W. Smith, and V. H. Holsinger. 1995. Flow and compaction of spray-dried powders of anhydrous butteroil and high melting milkfat encapsulated in disaccharides. J. Food Sci. 60:836-840. https://doi.org/10.1111/j.1365-2621.1995.tb06242.x.

Patra, Ch., R. Priya, S. Swain, G. Kumar Jena, K. Panigrahi, and D. Ghose. 2017. Pharmaceutical significance of Eudragit: A review. Future J. Pharmacol. Sci. 3:33-45. https://doi.org/10.1016/j.fjps .2017.02.001.

Poddar, D., S. Das, G. Jones, J. Palmer, G. Jameson, R. Haverkamp, and H. Singh. 2014. Stability of probiotic Lactobacillus paracasei during storage as affected by the drying method. Int. Dairy J. 39:1-7. https://doi.org/10.1016/j.idairyj.2014.04.007.

Pourjafar, H., N. Noori, H. Gandomi, A. A. Basti, and F. Ansari. 2020. Viability of microencapsulated and non-microencapsulated Lactobacilli in a commercial beverage. Biotechnol. Rep. (Amst.) 25:e00432. https://doi.org/10.1016/j.btre.2020.e00432.

Pyar, H., and K.-K. Peh. 2014. Enteric coating of granules containing the probiotic Lactobacillus acidophilus. Acta Pharm. 64:247-256. https://doi.org/10.2478/acph-2014-0011.

Rowe, R. C., P. J. Sheskey, and M. E. Quinn. 2009. Cellulose microcrystalline. Pages 129-133 in Handbook of Pharmaceutical Excipi- ents. 6th ed. American Pharmacists Association/Pharmaceutical Press, Chicago, IL.

Sandoval-Castilla, O., C. Lobato-Calleros, H. S. García-Galindo, L. Alvarez-Ramírez, and E. J. Vernon-Carter. 2010. Textural properties of alginate-pectin beads and survivability of entrapped $L b$. casei in simulated gastrointestinal conditions and in yoghurt. Food Res. Int. 43:111-117. https://doi.org/10.1016/j.foodres.2009.09 .010 .

Sareen, R., K. Nath, N. Jain, and K. Dhar. 2014. Curcumin loaded microsponges for colon targeting in inflammatory bowel disease: Fabrication, optimization, and in vitro and pharmacodynamic evaluation. BioMed Res. Int. 2014:340701. https://doi.org/10 $.1155 / 2014 / 340701$

Solanki, H. K., D. D. Pawar, D. A. Shah, V. D. Prajapati, G. K. Jani, A. M. Mulla, and P. M. Thakar. 2013. Development of microencapsulation delivery systems for long-term preservation of probiotics as biotherapeutics agent. BioMed Res. Int. 2013:620719. https: //doi.org/10.1155/2013/620719.

Stanton, C., G. Gardiner, H. Meehan, K. Collins, G. Fitzgerald, P. B. Lynch, and R. P. Ross. 2001. Market potential for probiotics. Am. J. Clin. Nutr. 73:476S-483S. https://doi.org/10.1093/ajcn/ $73.2 .476 \mathrm{~s}$.

Stummer, S., S. Toegel, M.-C. Rabenreither, F. M. Unger, M. Wirth, H. Viernstein, and S. Salar-Behzadi. 2012. Fluidized-bed drying as a feasible method for dehydration of Enterococcus faecium M74. J. Food Eng. 111:156-165. https://doi.org/10.1016/j.jfoodeng.2012 .01 .005 .

Tang, C., B. Xie, and Z. Sun. 2017. Antibacterial activity and mechanism of B-type oligomeric procyanidins from lotus seedpod on enterotoxigenic Escherichia coli. J. Funct. Foods 38:454-463. https:/ /doi.org/10.1016/j.jff.2017.09.046.

Vasisht, N. 2014. Selection of materials for microencapsulation. Pages 173-180 in. Microencapsulation in the Food Industry: A Practical Implementation Guide. A. Gaonkar, N. Visisht, A. Khare, and R. Sobel, ed. Academic Press, San Diego, CA.

Villa-García, M., R. Pedroza-Islas, R. Moreno-Terrazas, M. De la Rosa-Miranda, and A. Martínez-Ferez. 2010. Polidextrosa, inulina y aguamiel de maguey y su influencia en la sobrevivencia de Lactobacillus acidophilus microencapsulado en una mezcla de biopolímeros. BiopMat-Biopolímeros: fuentes, transformación, producción y aplicaciones innovadoras. Fundación para la Educación Superior Internacional, Veracruz, México.

Villena, M. J. M., F. Lara-Villoslada, M. A. R. Martínez, and M. E. M. Hernández. 2015. Development of gastro-resistant tablets for the protection and intestinal delivery of Lactobacillus fermentum CECT 5716. Int. J. Pharm. 487:314-319. https://doi.org/10.1016/ j.ijpharm.2015.03.078.

Wani, T. A., A. G. Shah, S. M. Wani, I. A. Wani, F. A. Masoodi, N. Nissar, and M. A. Shagoo. 2016. Suitability of different food grade materials for the encapsulation of some functional foods well reported for their advantages and susceptibility. Crit. Rev. Food Sci. Nutr. 56:2431-2454. https://doi.org/10.1080/10408398.2013 .845814 .

Yus, C., R. Gracia, A. Larrea, V. Andreu, S. Irusta, V. Sebastian, G. Mendoza, and M. Arruebo. 2019. Targeted release of probiotics from enteric microparticulated formulations. Polymers (Basel) 11:1668. https://doi.org/10.3390/polym11101668. 